\title{
Conduits Used in Coronary Artery Bypass Grafting: A Review of Morphological Studies
}

\author{
Brenda Martínez-González, MD, Cynthia Guadalupe Reyes-Hernández, MD, \\ Alejandro Quiroga-Garza, MD, Víctor E. Rodríguez-Rodríguez, MD, \\ Claudia N. Esparza-Hernández, MD, Rodrigo E. Elizondo-Omaña, MD, PhD, \\ and Santos Guzmán-López, MD, PhD
}

\begin{abstract}
There is a significant variety of vascular conduits options for coronary bypass surgery. Adequate graft selection is the most important factor for the success of the intervention. To ensure durability, permeability, and bypass function, there must be a morphological similarity between the graft and the coronary artery. The objective of this review was to analyze the morphological characteristics of the grafts that are most commonly used in coronary bypass surgery and the coronary arteries that are most frequently occluded. We included clinical information regarding the characteristics that determine the behavior of the grafts and its permeability over time. Currently, the internal thoracic artery is the standard choice for bypass surgery because of the morphological characteristics of the wall that makes less prone to developing atherosclerosis and hyperplasia. The radial and right gastroepiploic arteries are the following second and third best options, respectively. The ulnar artery is the preferred choice when other conduits are not feasible.
\end{abstract}

Keywords: conduits, coronary artery bypass grafting, histology, morphology, permeability

\section{Introduction}

Cardiovascular disease is the leading cause of death worldwide, accounting for $31 \%$ of all registered deaths, and is expected to continue in this position until 2030. ${ }^{1)}$ The most common of these is the coronary heart disease or coronary artery disease, ${ }^{2,3)}$ which represents the leading cause of death in developed countries.

Faculty of Medicine, Human Anatomy Department and University Hospital "Dr. Jose Eleuterio González", Universidad Autonoma de Nuevo León (UANL), Monterrey NL, Mexico

Received: July 24, 2016; Accepted: August 31, 2016

Corresponding author: Rodrigo E. Elizondo-Omaña, MD, PhD. Faculty of Medicine, Human Anatomy Department and University Hospital "Dr. Jose Eleuterio González", Universidad Autonoma de Nuevo León (UANL), Madero Avenue, Mitras Centro, Monterrey NL 64460, Mexico

Email: rod_omana@yahoo.com

(C)2017 The Editorial Committee of Annals of Thoracic and Cardiovascular Surgery. All rights reserved.
The main etiology of coronary artery disease is atherosclerosis, a multifactorial, chronic inflammatory process. Obstruction of blood flow is caused by plaques formed from fatty deposits in the walls of blood vessels and endothelium. The degree of obstruction of the vessel determines the treatment needed, either pharmacological or surgical. ${ }^{3)}$

Today, surgical treatment is widely used and it may vary from percutaneous angioplasty (coronary stent) to coronary artery bypass grafting $(\mathrm{CABG}){ }^{2,4)}$ This surgery has proven to be one of the most effective and lasting therapies for ischemic heart disease. ${ }^{3,5,6)}$ A lower mortality, better symptoms alleviation, and lower reoperation have been reported when compared to angioplasty. ${ }^{7)}$

Arteries or veins may be used in CABG as a graft to redirect blood to an area of the coronary artery, distal to the blockage. ${ }^{7)}$ The objectives of this procedure are to improve survival and alleviating symptoms. ${ }^{8}$ The main concern with this intervention is precisely the duration and functionality of the graft used. In order to achieve 
this, it is necessary to complete the revascularization using ducts that will remain permeable for all or most of the patient's life. ${ }^{4,9)}$

There is a wide variety of vascular conduits available for CABG. The most commonly used are as follows: internal thoracic artery (ITA), saphenous vein (SV), radial artery (RA), right gastroepiploic artery (RGEA), and occasionally ulnar artery (UA), splenic artery, and inferior epigastric artery. ${ }^{2)}$ Such diversity of options has caused controversy and a consensus regarding which one is superior has not been fully established. ${ }^{10)}$

The graft selection for the CABG is the most important factor in patient survival. ${ }^{2,6}$ This choice has been based on the surgeon's preference and experience, as well as the surgical protocols established by each hospital. ${ }^{11)}$ In order to determine the best choice, the surgeon must consider the patient's past medical history: age, cholesterol levels, smoking, and hypertension, among other comorbidities. ${ }^{8,10)}$ The morphological characteristics of the graft and the coronary arteries are also one of the most important criteria. ${ }^{4,10)}$

The morphological similarity between the graft and the coronary artery is important in order to promote durability, permeability, and good functioning of the bypass. ${ }^{10,12)}$ The most important morphological features to consider are length, luminal diameter, wall thickness, and histological characteristics of the conduit. ${ }^{4,10)}$

The objective of this review is to analyze the morphological characteristics of the conduits used in CABG: the SV, ITA, RA, UA, and RGEA. The most frequently occluded coronary arteries used are as follows: anterior interventricular artery (AIA), circumflex artery (CX), and right coronary artery (RCA). ${ }^{13-16)}$ For each vessel, the following parameters are reviewed: length, luminal diameter, thickness of the intima and media, and histological features of the wall. Clinical information regarding the characteristics that determine the behavior of the grafts during surgery and its permeability over time is also provided.

\section{Coronary arteries}

The coronary arteries' segments that have a higher incidence of occlusions are AIA, CX, and RCA. ${ }^{13-16)}$ There is insufficient evidence evaluating the specific segments of the coronary arteries where atheromas are most often located, or their size. It is reported that most atheromas occupy the proximal segments, ${ }^{13,17)}$ and these are usually the largest. ${ }^{17)}$ This is most likely because these segments have a greater luminal diameter. Atheromas' size is important because the severity of coronary artery disease is one of the factors that determine the graft selection for CABG. ${ }^{10)}$

The coronary arteries' anatomy and its variants are well described in the literature. The anatomical variations many times influence the method indicated for CABG. The most common is the right coronary dominance, with a prevalence of between $76 \%$ and $85 \%$, followed by the balanced circulation with a frequency of $7.5 \%-17 \%$, and finally left dominance with $6.8 \%-7.5 \%$ prevalence. ${ }^{17-19)}$ Morphological characteristics of each artery from several studies are described in Table $\mathbf{1 .}$

There are few studies reporting the length of the coronary arteries, which may vary between populations. ${ }^{17,20)}$ A study in Turkish population reported a mean length of $9.38 \pm 1.84 \mathrm{~cm}$ for AIA, $6.60 \pm 1.53 \mathrm{~cm}$ in RCA, and $5.70 \pm 1.20 \mathrm{~cm}$ in $\mathrm{CX}^{20)}$ In contrast, a study involving a Mexican population reported mean lengths of $15.66 \pm$ $1.12 \mathrm{~cm}$ for AIA, $12.69 \pm 1.94 \mathrm{~cm}$ for RCA, and $8.89 \pm$ $2.11 \mathrm{~cm}$ for CX. ${ }^{17)}$

The luminal diameter is the most studied and irregular parameter. Most studies only analyzed a single segment, ${ }^{19-23)}$ whereas others analyzed the segments that are most often occluded ${ }^{17)}$ or an unspecified segment (Barry et al., 200724); Ballesteros and Ramirez, 2008 ${ }^{25}$ ) (Table 1).

The thickness of the intima and tunica media is rarely evaluated (Table 1). The AIA, RCA, and CX are muscular arteries, with a tunica media bounded by two distinct internal and external elastic laminae. ${ }^{21,24)}$ The amount of elastic fibers in the tunica media is low, being only $2-7$ fibers. ${ }^{17)}$

\section{Saphenous vein}

Favaloro (1968) reported the first CABG using the SV as a graft. ${ }^{426)}$ During the first decades, the SV was the most used conduit, as it has sufficient length and diameter, coupled with the absence of atheromas, ${ }^{2)}$ and it is easily available. ${ }^{27)}$ However, because the permeability is compromised due to its adaptive histological changes such as intimal hyperplasia and atherosclerosis, $5,27,28)$ arterial grafts have demonstrated to be superior to venous. ${ }^{2,4,27)}$ Thus, international guidelines recommend arterial conduits, specifically the ITA, as the gold standard. ${ }^{2,8,29)}$

However, the use of vein grafts has gradually increased in recent years. ${ }^{30)}$ This may be due to the development of the "no touch" vein harvest technique. This procedure involves harvesting a SV with the perivascular tissue intact without direct contact or manipulation of the vein 
Table 1 Morphological studies on the coronary arteries that occlude most frequently

\begin{tabular}{|c|c|c|c|c|c|}
\hline \multirow[b]{2}{*}{ Author } & \multirow[b]{2}{*}{ Sample } & \multirow[b]{2}{*}{ Vessel } & \multicolumn{3}{|c|}{ Results } \\
\hline & & & \multicolumn{2}{|c|}{ Luminal diameter (mm) } & $\begin{array}{l}\text { Tunic thickness of the } \\
\text { intima media }(\mu \mathrm{m})\end{array}$ \\
\hline \multirow[t]{3}{*}{ Barry et al., 200321) } & 20 cadavers & AIA & M: $1.6(1-3)$ & & \\
\hline & & $\mathrm{RCA}$ & P: $3.2(2.5-4.5)$ & & \\
\hline & & $\mathrm{CX}$ & $\mathrm{U}: 2(1-5.3)$ & & \\
\hline \multirow[t]{3}{*}{ Unlü et al., 200320) } & 7 cadavers & AIA & $\mathrm{M}: 2.53 \pm 0.86$ & & M: $299 \pm 42$ \\
\hline & 8 autopsies & $\mathrm{RCA}$ & M: $1.98 \pm 0.67$ & & M: $226 \pm 36$ \\
\hline & 14 patients & $\mathrm{CX}$ & M: $1.62 \pm 0.44$ & & M: $271 \pm 33$ \\
\hline \multirow[t]{2}{*}{ Barry et al., 200724) } & 40 cadavers & AIA & $\mathrm{U}: \quad 1.6 \pm 0.3$ & & \\
\hline & & $\mathrm{CX}$ & $\mathrm{U}: \quad 2.2 \pm 0.4$ & & \\
\hline \multirow[t]{3}{*}{ Ballesteros et al., 2008²) } & 154 cadavers & AIA & $\mathrm{U}: 2.94 \pm 0.5$ & & \\
\hline & & $\mathrm{RCA}$ & $\mathrm{U}: \quad 3.8 \pm 0.52$ & & \\
\hline & & $\mathrm{CX}$ & $\mathrm{U}: 2.71 \pm 0.54$ & & \\
\hline \multirow[t]{3}{*}{ Ballesteros et al., 2011 ${ }^{19)}$} & 221 cadavers & $\mathrm{RCA}$ & $P: 3.42 \pm 0.66$ & & \\
\hline & & & D: $\quad 2.0 \pm 0.5$ & & \\
\hline & & & Men & Women & \\
\hline \multirow[t]{5}{*}{ Ilayperuma et al., 201122) } & 102 cadavers & AIA & $P: 3.96 \pm 0.99$ & $P: 3.72 \pm 1.18$ & \\
\hline & & $\mathrm{RCA}$ & $P: 5.99 \pm 1.23$ & $P: 4.73 \pm 1.82$ & \\
\hline & & & M: $5.28 \pm 1.45$ & M: $4.32 \pm 1.92$ & \\
\hline & & $\mathrm{CX}$ & $P: 3.94 \pm 1.34$ & $P: 3.73 \pm 0.78$ & \\
\hline & & & Men & Women & \\
\hline \multirow[t]{3}{*}{ Aroche et al., 2013 23 ) } & 386 angiographs & AIA & $P: 3.59 \pm 0.69$ & $P: 3.68 \pm 0.83$ & \\
\hline & & $\mathrm{RCA}$ & $P: 3.46 \pm 0.67$ & $P: 3.16 \pm 0.89$ & \\
\hline & & $\mathrm{CX}$ & P: $3.24 \pm 1.05$ & $P: 3.25 \pm 0.88$ & \\
\hline \multirow[t]{7}{*}{ Martínez et al., 20157) } & 11 cadavers & AIA & P: $2.37 \pm 0.47$ & & P: $354.39 \pm 98.72$ \\
\hline & & & $\mathrm{M}: 1.50 \pm 0.31$ & & M: $218.79 \pm 113.36$ \\
\hline & & & $\mathrm{D}: 1.12 \pm 0.31$ & & D: $117.59 \pm 34.41$ \\
\hline & & $\mathrm{RCA}$ & $P: 2.31 \pm 0.76$ & & P: $396.31 \pm 105.47$ \\
\hline & & & $\mathrm{D}: 1.81 \pm 0.43$ & & D: $305.52 \pm 111.08$ \\
\hline & & $\mathrm{CX}$ & $P: 2.33 \pm 0.57$ & & P: $361.37 \pm 132.42$ \\
\hline & & & D: $1.51 \pm 0.43$ & & D: $227.59 \pm 118.11$ \\
\hline
\end{tabular}

This table shows the results of various morphological studies on the coronary arteries that occluded most frequently. AIA: anterior interventricular artery; RCA: right coronary artery; CX: circumflex artery; P: proximal segment; M: medial segment; D: distal segment; U: single segment/unspecified

itself, thus avoiding distension prior to anastomosis, ${ }^{31,32)}$ which can cause intimal and medial hyperplasia, leading to graft failure. ${ }^{31)}$

When using conventional or manual dilatation technique, the SV is often stripped of its adventitial layer and distended, causing damage to the wall. ${ }^{33)}$ The luminal diameter of the vein increases, causing the loss of the characteristic folds in the tunica intima, ${ }^{31)}$ as well as modifications in the tunica media morphology and smooth muscle cell distribution. ${ }^{31)}$ Also these cells are genetically activated, which lead to an increased and uncontrolled proliferation and migration to the tunica intima, diminishing the graft permeability. ${ }^{31)}$

In contrast, when the "no touch" harvesting technique is used, it provides better structural, functional, and mechanical protection of the vein wall, resulting in a long-term improvement. ${ }^{33)}$ The morphological characteristics of the vein, such as the luminal diameter, ${ }^{31)}$ the collagen in the tunica adventitia, ${ }^{32}$ the circular distribution pattern of the smooth muscle cells in the tunica media, ${ }^{31)}$ and the endothelium in the tunica intima, remain intact. ${ }^{32)}$ The vasa vasorum and the expression of the nitric oxide synthase in the tunica intima increase, whereas the atherosclerotic process is reduced. ${ }^{32)}$

Studies using a "no touch" or low manipulation technique report that long-term results are similar and compatible to those of arterial grafts. ${ }^{9)}$ Permeability rates using this procedure are of $83 \%$ at 16 years compared to an $88 \%$ in arterial grafts. ${ }^{9)}$

Regarding the morphology of the SV, a Turkish study reported a mean length of $72.42 \pm 6.60 \mathrm{~cm} .^{20)}$ The luminal diameter varies in proximal, medial, and distal segment 
with $5.24 \pm 0.62 \mathrm{~mm}, 3.25 \pm 0.51 \mathrm{~mm}$, and $1.67 \pm 0.29 \mathrm{~mm}$, respectively. ${ }^{20)}$ The thickness of the media and intima also varies, with $291 \pm 35 \mu \mathrm{m}, 200 \pm 31 \mu \mathrm{m}$, and $143 \pm$ $32 \mu \mathrm{m}$, respectively, for each segment. ${ }^{20)}$

The SV has a thin intima covered by a layer of endothelial cells. It is separated from the tunica media by a rudimentary internal elastic lamina, which is discontinuous and irregular. Its tunica media contains two layers of smooth muscle cells, a thick internal layer made up of longitudinal collagen fibers, and a thick outer circular layer. ${ }^{34-36)}$ The internal longitudinal layer is thicker when valves are present. ${ }^{35,36)}$ The adventitia is composed of connective tissue, collagen and elastic fibers, and longitudinal smooth muscle cell fibers. ${ }^{34-36)}$ It also has vasa vasorum, which can reach the tunica media. ${ }^{34}$

Various studies report the changes in the vein's morphology prior to its use as a graft in CABG..$^{35,37,38)}$ The changes reported are as follows: fibrosis of the intima with the presence of elastic fibers, collagen, and smooth muscle cells, causing narrowing of the lumen; elastosis of the internal elastic lamina, and hypertrophy of the longitudinal layer of the tunica media. . $^{35,37,38)}$ These changes may have implications for graft failure, contributing to the development of cell proliferation in the intima, thus causing graft occlusion. ${ }^{35,37)}$

The changes that occur in the intima are associated with the changes in the tunica media; this indicates that there is a common etiology. ${ }^{37,38)}$ Although these injuries are considered part of the aging process, the study by Thiene et al. (1980) analyzed $150 \mathrm{SV}$ prior to CABG, dividing patients by age, and revealed that these changes do not correlate with the age of patients. They also recommended reviewing the morphology of the vein prior to use, to discard useless grafts and use alternative conduits. ${ }^{35)}$ The permeability of the $\mathrm{SV}$ is $50 \%-60 \%$ at 10 years $^{2,4,28)}$ and $20 \%$ at 20 years. ${ }^{28)}$ Graft failure causes recurrent ischemic symptoms and clinical deterioration, requiring new revascularization procedures, which are less effective and generate higher risks and costs. ${ }^{26)}$

\section{Internal thoracic artery}

Vineberg (1946) was the first to use the ITA as a graft in CABG. ${ }^{2,39)}$ Currently, it is considered the standard for $\mathrm{CABG}$ and is recognized by cardiothoracic surgeons as the most effective and reliable conduit due to its excellent permeability, lower incidence of adverse events, and greater long-term survival for the patient. ${ }^{2,4,5,8,29,40-42)}$ The higher permeability of this conduit is attributed to the morphological characteristics of the wall,,$^{, 40-43)}$ as its histological structure makes it relatively free of atherosclerosis as well as from intimal hyperplasia. ${ }^{29,40-44)}$

Both left and right ITAs can be used either in situ or as a free graft. ${ }^{529)}$ The left ITA is used more often than the right because of its location and proximity to the heart, allowing for a better anastomosis. ${ }^{2)}$ Using the left ITA to re-establish circulation to the AIA remains unchallenged in the CABG. ${ }^{2,5)}$ When AIA does not need revascularization, it is used to revascularize the most important coronary artery. ${ }^{5)}$ The right ITA may be used to revascularize branches of the left coronary or branches of the CX; however, it is inaccessible for hemostasis or verification of permeability. Because of this, it is commonly used to bypass the RCA in its middle or distal segment, or if its length is sufficient, the posterior interventricular artery (PIA). ${ }^{5)}$

Morphological studies report that the ITA does not present a uniform structure along its length, and is known as a transitional artery. ${ }^{40-43)}$ This may have implications regarding its use and thus interfere with the results of $\mathrm{CABG},{ }^{44)}$ and this is the reason why the morphology of specific segments is important. There are studies that evidence differences between the left and right ITA, ${ }^{42)}$ as well as they report similarities in their structure. ${ }^{44)}$

This vessel has a reported length ranging from 14.32 to $19.48 \mathrm{~cm} .{ }^{4,20,45)}$ A study by Henriquez et al. using 100 bodies demonstrated that the length difference between the two ATI was minimal, reporting $20.7 \mathrm{~cm}$ in the left and $20.1 \mathrm{~cm}$ in the right. ${ }^{45)}$

Results of various morphological studies of ITA, where the luminal diameter and the thickness of the tunica intima and media are determined, are shown in Table 2. The luminal diameter in the proximal segment varies from 2.12 to $2.75 \mathrm{~mm}$ and $1.03 \mathrm{~mm}$ to $1.75 \mathrm{~mm}$ in the distal segment. ${ }^{20,46)}$ Comparative studies of the right and left ITA report a luminal diameter of $1.72 \mathrm{~mm}$ and $1.76 \mathrm{~mm}$, respectively. ${ }^{12)}$ Although in studies in which unspecified segments were evaluated, the luminal diameter ranged between 1.6 and $2.75 \mathrm{~mm} .^{4,5,21,24)} \mathrm{In}$ studies in which the artery segment evaluated is not specified, a wall thickness of $350 \mu \mathrm{m}$ is reported..$^{5,41)}$

The amount of elastic fibers in the tunica media varies along with the length of the ITA. ${ }^{41,43)}$ The middle segment is the one with the most elastic fibers present, with nine fibers; the proximal segment has six fibers, and the distal segment three fibers. ${ }^{41)}$ Comparative studies show that there are significant differences in the amount of elastic fibers between the two ITA, being higher on the left than on the right. ${ }^{42)}$ Other studies that 
Table 2 Morphological studies on the internal thoracic artery

\begin{tabular}{|c|c|c|c|c|}
\hline \multirow[b]{2}{*}{ Author } & \multirow[b]{2}{*}{ Sample } & \multicolumn{3}{|c|}{ Results } \\
\hline & & $\begin{array}{l}\text { Luminal diameter } \\
\qquad(\mathrm{mm})\end{array}$ & $\begin{array}{l}\text { Tunic thickness of the } \\
\text { intima media }(\mu \mathrm{m})\end{array}$ & $\begin{array}{l}\text { Number of } \\
\text { elastic fibers }\end{array}$ \\
\hline Barry et al., 200321) & 20 cadavers & $\mathrm{U}: 1.5(1-2.5)$ & & \\
\hline \multirow[t]{2}{*}{ Unlü et al., 2003 20) } & 7 cadavers & $P: 2.12 \pm 0.27$ & $P: 253 \pm 43$ & \\
\hline & $\begin{array}{l}8 \text { autopsies } \\
14 \text { patients }\end{array}$ & $\mathrm{D}: 1.03 \pm 0.17$ & D: $139 \pm 37$ & \\
\hline Kneubil et al., 200640) & 18 cadavers & & U left: $218.3-257.7$ & $13.1-20.4$ \\
\hline Barry et al., 200724) & 40 cadavers & $\mathrm{U}: 1.6 \pm 0.3$ & & \\
\hline \multirow[t]{2}{*}{ Ribeiro et al., 2008 } & 18 cadavers & & U right: 156-262 & $10-16$ \\
\hline & & & U left: 205-270 & $12-21$ \\
\hline Borović et al., 2010 & $\begin{array}{c}42 \text { arteries of } \\
\text { autopsies }\end{array}$ & & U: 12.57-22.15 & \\
\hline \multirow[t]{2}{*}{ Appleson et al., 2012 } & 7 cadavers & U right: 1.72 & $\mathrm{U}: 0.22$ & 27.20 \\
\hline & & U left: 1.76 & $\mathrm{U}: 0.17$ & 30.31 \\
\hline \multirow[t]{2}{*}{ Kinoshita et al., 201444) } & 144 segments & U right: 1.60 & $\mathrm{U}: 172$ & \\
\hline & & U left: 1.52 & U: 169 & \\
\hline
\end{tabular}

This table shows the results of various morphological studies of ITA. P: proximal segment; D: distal segment; $\mathrm{U}$ : single segment/unspecified

determine the number of elastic fibers in the ITA are shown in Table 2.

Histologically, the ITA is an elastic artery, $5,21,24,43)$ which could explain its excellent long-term patency, as it is mentioned that, the more elastic the graft is, the greater its permeability will be over time. ${ }^{10)}$ The intima is thin and the tunica media is delimited by a thick and welldefined internal elastic lamina. ${ }^{5,43)}$ The tunica media has two sublayers: an internal and an external layer. ${ }^{43)}$ The internal layer is muscular, composed mainly of smooth muscle cells with few elastic fibers that are not well formed. ${ }^{43)}$ The external layer is elastic, composed mainly of well-defined elastic fibers with few muscle cells. ${ }^{43)}$ The compact structure of the internal elastic lamina is a possible explanation for the low incidence of developing intimal hyperplasia. ${ }^{43}$

The permeability of the ITA is superior to that of all other conduits used in CABG., ${ }^{2,5,28,40-42)}$ The left ITA, when anastomosed with the AIA, has a permeability of $99 \%$ at 5 years, $97 \%$ at 10 years, $90 \%-95 \%$ at 15 years, and $90 \%$ at 20 years. ${ }^{2,4,5,28)}$ When anastomosed with the CX, its permeability is $97 \%$ at 5 years, $92 \%$ at 8 years, $89 \%$ at 10 years, $\left.{ }^{4}\right)$ and $91 \%$ at 15 years. ${ }^{5)}$ When anastomosed with the RCA, permeability descends to $84 \%$ at 15 years. ${ }^{5)}$ The right ITA has a permeability of $80 \%-90 \%$ at 10 years when anastomosed with the RCA. ${ }^{2)}$ Other studies report a $91.9 \%$ permeability with the AIA, $90.1 \%$ with the CX, and $83.1 \%$ with RCA. ${ }^{47)}$

\section{Radial artery}

Carpentier (1973) was the first to use RA for $\mathrm{CABG}, 2,4,47-49)$ and is currently considered the second best conduit after the ITA. ${ }^{4,5,47,50)}$ In recent years, it has gained popularity as a graft for CABG because of its multiple morphological and surgical advantages that make it superior to other conduits. ${ }^{4,5,50,51)}$

The features that make it a versatile graft for $\mathrm{CABG}$ are as follows: its vast length to reach distal coronary branches and perform multiple anastomoses, ${ }^{4,5,47,48,50)}$ a thickness that makes it comfortable to handle and easy to anastomose, ${ }^{4,5,48,50)}$ a diameter comparable to the coronary arteries, ${ }^{4,47,48,50)}$ its ability to adapt to high blood pressure, ${ }^{48)}$ its removal is safe and easy, ${ }^{4,5,47,48,52)}$ and a remarkable permeability at short, medium, and long term. . $^{2,4,5,47,52)}$

On the other hand, the RA does have some disadvantages; the important one is that due to its thick muscular tunica media, it is prone to early spasms. $4,5,47,48,50,51)$ However, the use of specific surgical techniques and pharmacological prophylaxis may prevent it. ${ }^{5,47)}$ Additionally, the prevalence of atherosclerosis and intimal hyperplasia is higher in RA than in the ITA and it can also present calcification in the tunica media (Monckeberg's Sclerosis) with a prevalence of $25 \% .50,51)$

The most widely accepted indication for RA use is revascularization of the second most important coronary artery in patients where the use of both ITA is contraindicated.5) Usually, it is anastomosed with the RCA,2,45) 
Table 3 Morphological studies on the radial artery

\begin{tabular}{|c|c|c|c|c|}
\hline \multirow[b]{2}{*}{ Author } & \multirow[b]{2}{*}{ Sample } & \multicolumn{3}{|c|}{ Results } \\
\hline & & Length $(\mathrm{cm})$ & $\begin{array}{l}\text { Luminal diameter } \\
\qquad(\mathrm{mm})\end{array}$ & $\begin{array}{l}\text { Tunic thickness of the } \\
\text { intima media }(\mu \mathrm{m})\end{array}$ \\
\hline Barry et al., 200321) & 20 cadavers & & $\mathrm{U}: 2.2(1-2.5)$ & \\
\hline Riekkinen et al., 200355) & $\begin{array}{l}\text { Angiographs } \\
\text { of } 24 \text { cadavers }\end{array}$ & & D left: $3.0 \pm 0.5$ & \\
\hline & & & D right: $3.2 \pm 0.5$ & \\
\hline Unlü et al., 2003²0) & $\begin{array}{l}7 \text { cadavers } \\
8 \text { autopsies } \\
14 \text { patients }\end{array}$ & $22.28 \pm 3.31$ & $\mathrm{U}: 2.20 \pm 0.26$ & $\begin{array}{l}P: 321 \pm 32 \\
D: 161 \pm 43\end{array}$ \\
\hline Appleson et al., 2012 & 7 cadavers & & $\mathrm{U}: 2.39$ & $\mathrm{U}: 254$ \\
\hline Nasr, 2012 & 50 cadavers & $\begin{array}{c}\text { Men } \\
22.6 \pm 21.7\end{array}$ & $\begin{array}{c}\text { Men } \\
\text { P: } 3.3 \pm 0.72 \\
\text { D: } 3.1 \pm 0.73\end{array}$ & \\
\hline & & $\begin{array}{c}\text { Women } \\
20.9 \pm 13.9\end{array}$ & $\begin{array}{ll} & \text { Women } \\
\text { P: } & 3.2 \pm 0.66 \\
\text { D: } & 3.0 \pm 0.66\end{array}$ & \\
\hline Reyes et al., 2013 ${ }^{48)}$ & 10 cadavers & $21.94 \pm 3.34$ & $\begin{array}{ll}P: & 1.48 \pm 0.70 \\
\text { M: } & 1.01 \pm 0.35 \\
\text { D: } 1.43 \pm 0.47\end{array}$ & $\begin{array}{l}\text { P: } 196.16 \pm 72.35 \\
\text { M: } 148.25 \pm 40.40 \\
\text { D: } 158.96 \pm 45.74\end{array}$ \\
\hline
\end{tabular}

This table shows the results of various morphological studies of ITA. P: proximal segment; M: medial segment;

D: distal segment; U: single segment/unspecified

CX, or PIA ${ }^{4,5)}$ and its use in these vessels has been associated with satisfactory clinical and angiographic results. ${ }^{4)}$ Less frequently, it has been used to anastomose with diagonal branches or to bypass the AIA.5)

Complications in the forearm after extraction are rare when adequate preoperative assessment is preformed. ${ }^{4,5,47,48)}$ Sensory neurological disorders are rare ${ }^{4,5)}$ with incapacitating symptoms present in less than $10 \%$ of patients, with most cases disappearing within days or weeks. ${ }^{5)}$

After grafting the RA in $\mathrm{CABG}$, it undergoes functional and morphological remodeling characterized by increased luminal diameter, decreased muscle thickness with a conduit transformation from muscular to elastic/ muscular, and initial loss of reactivity; these changes make it even more suitable as a graft for CABG. ${ }^{50)}$ It is reported that the main cause of graft failure is spasm or hyperplasia. ${ }^{51)}$

Results of various morphological studies of the RA, where the length, luminal diameter, and thickness of the tunica intima and media are determined, are shown in Table 3. Reportedly, it has a length between 20 and $22.6 \mathrm{~cm} .4,20,46-48,50,52)$ The luminal diameter reported in studies that do not specify the evaluated segment varies between 2 and $3 \mathrm{~mm} \cdot{ }^{12,20,21,47)}$ The wall thickness reported in studies do not specify the segment evaluated, varying from 254 to $529 \mu \mathrm{m} .{ }^{12,41)}$
Histologically, the RA is a muscular artery. ${ }^{5,21,24,41)}$ It has a thin intima presenting mild to moderate hyperplasia ${ }^{5)}$ and a thick tunica media with abundant smooth muscle cells. ${ }^{4,5,41,47,51)}$ Reportedly, it has an $18.84 \%$ of elastic fibers in the tunica media. ${ }^{12)}$ Its internal elastic lamina is well defined and developed ${ }^{21)}$ although other studies mention the presence of multiple fenestrations, which would explain their susceptibility to atherosclerosis. ${ }^{5,47)}$ Its vasa vasorum does not penetrate the tunica media, assuming it does not require arterial supply, making it ideal for free graft use. ${ }^{4}$ )

Studies have demonstrated that the RA has comparable clinical results to the ITA when used as a second graft, and has a better outcome when compared to the SV. ${ }^{5)}$ Complications are infrequent and it has a lower preoperative morbidity. ${ }^{5)}$ It also has a lasting permeability ${ }^{2,4,5,47,52)}$ and does not appear to be influenced by the target conduit when anastomosed. ${ }^{4,47)}$

It has a permeability of $90 \%-95 \%$ in the first year, ${ }^{2,5,50)}$ $91 \%$ at 3 years, ${ }^{50)} 87 \%-95 \%$ at 5 years, ${ }^{28)} 83 \%$ at 7 years, $82 \%$ at 8 years, ${ }^{50)}$ and $72 \%-84 \%$ at 10 years. ${ }^{53)}$ When it is anastomosed with the AIA, permeability is $87 \%$ (significantly lower than the ITA), when used with the CX, permeability is maintained at $92 \%$ (similar to the ITA), and when used with the RCA or PIA, permeability is maintained at $88 \%$ (greater than the right ITA). ${ }^{4}$ In addition, it is reported that $86 \%$ of patients were free of angina after 5 years $^{2)}$ and that mortality is less than $\left.1 \%-2 \%{ }^{4}\right)$ 
Table 4 Morphological studies on the ulnar artery

\begin{tabular}{|c|c|c|c|}
\hline \multirow{2}{*}{ Author } & \multirow{2}{*}{ Sample } & \multicolumn{2}{|r|}{ Results } \\
\hline & & Length (cm) & Luminal diameter ( $\mathrm{mm}$ ) \\
\hline Buxton et al., 199854) & 8 patients & 15 & $\mathrm{U}: 2-3$ \\
\hline \multirow[t]{2}{*}{ Riekkinen et al., 200355) } & Angiographs of & & U left: $2.4 \pm 0.5$ \\
\hline & 24 cadavers & & U right: $2.5 \pm 0.5$ \\
\hline \multirow[t]{3}{*}{ Hinojosa et al., 2005 } & 10 cadavers & $19.02 \pm 1.88$ & $\mathrm{P}: 2.45 \pm 0.09$ \\
\hline & & & M: $2.19 \pm 0.09$ \\
\hline & & & D: $1.96 \pm 0.09$ \\
\hline Necomb et al., 2006 56 ) & 25 patients & 18 & $\mathrm{U}: 2.4$ \\
\hline Barry et al., 200724) & 40 cadavers & & $\mathrm{U}: 2.4$ \\
\hline
\end{tabular}

This table shows the results of various morphological studies of the AU. P: proximal segment; M: medial segment; D: distal segment; U: single segment/unspecified

\section{Ulnar artery}

Buxton et al. (1998) were the first to use UA as a graft in $\mathrm{CABG} .^{2,454)}$ Its use as a graft is not popular because the RA is preferred; this is due to studies that establish UA as the dominant artery in the forearm. ${ }^{2,4,54-56)}$ It is thought that its removal could result in functional disorders of the hand. ${ }^{2)}$ However, it has been used in surgical procedures of myocardial revascularization surgery and reconstruction with few local implications. ${ }^{4)}$

The use of the UA is limited to cases where the use of other conduits is not feasible ${ }^{2,56)}$ or when it is not considered safe to extract the RA. ${ }^{4,56)}$ Likewise, when the RA is the dominant blood supply to the hand, which may be the case in $5 \%-10 \%$ of cases. ${ }^{54}$ Other authors have proven the RA has increased flow and is larger than the UA, that is why it should be considered the dominant artery of the hand. ${ }^{4,55,56)}$ To determine the dominant artery of the forearm, appropriate clinical evaluation should be performed previous to the intervention, in order to have a safe extraction and lower risks. ${ }^{56}$

The UA can be removed from forearm safely, it is similar to the RA in characteristics of length and diameter size, which make it an ideal conduit for coronary graft use. ${ }^{56,57)}$ The biggest concern in relation to its use is the risk of injury to surrounding structures such as the ulnar nerve or ischemia of such structure due to section of the vasa nervorum. ${ }^{4,56-58)}$ Another possible complication is the spasm of the artery because like RA, the tunica media is thick and muscular predominance. ${ }^{57)}$

Results of morphological studies of the UA, where the length and luminal diameter are determined, are shown in Table 4. There is no evidence on the thickness of the intima and media and scarce information about its histological structure, reporting only that it is a muscular artery. ${ }^{24,60)}$
The use of the UA is safe and sensory deficit is uncommon, plus morbidity is low and there is no evidence of myocardial ischemia. ${ }^{4,56)}$ The permeability is comparable to that of RA. ${ }^{57)}$ Because there is limited experience and studies regarding this conduit, ${ }^{2,54)}$ there is a lack of clinical evidence about long-term results, to indicate the effectiveness and permeability of this vessel as a graft in the $\mathrm{CABG}{ }^{2,56)}$

\section{Right gastroepiploic artery}

Bailey et al. (1967) first used RGEA as a conduit for myocardial implementation in 1966. ${ }^{2.59)}$ Sterling Edwards (1973) first used it as a bypass for RCA, but there are no reports on carrying out the process. ${ }^{2,60)}$ In 1984 , Pym et al. were the first to report its use for revascularization of the posterior marginal artery and RCA.,61,62) Due to the satisfactory results, this vessel is still considered an option for CABG. ${ }^{62}$

The RGEA is considered the third option for CABG. ${ }^{2)}$ It is a very versatile conduit, it provides $20 \mathrm{~cm}$ in length, and is capable of reaching all the areas of the heart. ${ }^{5)}$ However, there are some concerns in its use: its small size and its propensity to vasospasm. ${ }^{63)}$

The RGEA is mainly used for revascularization of the lower side of the heart, ${ }^{5)}$ particularly the PIA, ${ }^{5,61)}$ and appears to be the ideal conduit for this area. ${ }^{61)}$ It is also used in distal segment of the RCA, and less frequently for marginal branches of the CX and the distal AIA. ${ }^{5)}$ It is occasionally dissected and skeletonized to be used as in situ graft, and more frequently left with the gastroepiploic vein and fatty tissue to be used as a pedicle. ${ }^{61)}$

In most patients, it is used in conjunction with the left ITA and the RA in an attempt to achieve complete revascularization of different coronary vessels. ${ }^{5)}$ More commonly, it used as a free graft and can revascularize more 
Table 5 Studies on the right gastroepiploic artery

\begin{tabular}{|c|c|c|c|c|}
\hline \multirow[b]{2}{*}{ Author } & \multirow[b]{2}{*}{ Sample } & \multicolumn{3}{|c|}{ Results } \\
\hline & & $\begin{array}{l}\text { Luminal diameter } \\
\qquad(\mathrm{mm})\end{array}$ & $\begin{array}{l}\text { Tunic thickness of the } \\
\text { intima media }(\mu \mathrm{m})\end{array}$ & $\begin{array}{l}\text { Number of } \\
\text { elastic fibers }\end{array}$ \\
\hline Unlü et al., 2003²0) & $\begin{array}{l}7 \text { cadavers } \\
8 \text { autopsies } \\
14 \text { patients }\end{array}$ & $\mathrm{U}: 1.62 \pm 0.45$ & $\begin{array}{l}P: 274 \pm 35 \\
D: 119 \pm 29\end{array}$ & \\
\hline Appleson et al., 201212) & 7 cadavers & $\mathrm{U}: 1.35$ & U: 190 & $21.42(\%)$ \\
\hline Van Phung et al., 201263) & 33 patients & D: 3.8 & D: 250 & D: $4.2 \pm 1.8$ \\
\hline
\end{tabular}

This table shows the results of various morphological studies of RGEA. P: proximal segment; D: distal segment; $\mathrm{U}$ : single segment/unspecified.

than one artery by one or more side anastomosis. ${ }^{5)}$ The anastomosis with the AIA has poor results and should be avoided. ${ }^{64)}$

The only absolute contraindication for its use is a previous partial or complete gastrectomy. ${ }^{61)}$ Abdominal complications due to extraction are rare. ${ }^{64)}$ No complications have been reported on the risk of deprivation of blood supply to the greater curvature of the stomach. ${ }^{5)}$ One concern is the potential damage of the graft or spasm during abdominal surgery. ${ }^{62)}$ The main mechanism of graft failure is a reduction in intraluminal diameter or occlusion when used for revascularized arteries with low-grade stenosis. ${ }^{5)}$

Results of morphological studies of RGEA are shown in Table 5. There is limited information on their morphology. It has a length of $19.32-20 \mathrm{~cm}^{.20,61)}$ In the proximal segment, diameter varies from 2.5 to $2.7 \mathrm{~mm}$, 5,41$)$ $2.2 \pm 0.4 \mathrm{~mm}$ in the middle segment, ${ }^{41)}$ and $1.8-3.8 \mathrm{~mm}$ in the distal segment, which varies greatly. ${ }^{5,41,63)}$

In the proximal segment, thickness varies between 274 and $305 \mu \mathrm{m},{ }^{20,41)} 290 \mu \mathrm{m}$ in the middle segment, ${ }^{41)}$ and 119 and $250 \mu \mathrm{m}$ in the distal segment. ${ }^{20,41,63)}$ It is a muscular artery, it has an internal elastic lamina with fenestrations and a tunica intima with slight hyperplasia. ${ }^{5,41)}$

The permeability of the short-term RGEA is comparable to that of ITA, but long term is similar to that of the SV. ${ }^{5,64)}$ There are reports of $97 \%$ at 13 months, ${ }^{2)}$ $92 \%-80 \%$ at 5 years, ${ }^{2,5)}$ and $60 \%$ at 10 years. ${ }^{5)}$ However, it has good permeability, that is, both short and long term when anastomosed with the RCA, ${ }^{64)}$ with $98 \%$ in the first year, $84 \%$ at 3 years, ${ }^{5)} 80 \%-90 \%$ at 5 years, and $62 \%$ at 10 years. ${ }^{64)}$

\section{Other conduits}

Less frequently, other arteries are used as grafts in CABG. It is resorted to when, for various reasons, the previously mentioned arteries are not available or cannot be used for revascularization. ${ }^{565)}$ Among other conduits used are as follows: inferior epigastric artery, splenic artery, subscapular artery, inferior mesenteric artery, intercostal arteries, and the descending branch of the lateral femoral CA. ${ }^{65)}$ The most commonly used of these is the inferior epigastric artery.5)

\section{Conclusion}

There is a wide variety of conduits used as vascular grafts in CABG. Their careful selection is important to ensure its long-term patency. Morphological similarity between the graft and the coronary artery is the most important factor. The features to consider are: as follows length, luminal diameter, wall thickness, and histological characteristics of the vessel.

The most frequently occluded coronary arteries are AIA, RCA, and CX. They are muscular arteries, and their luminal diameter has been the most studied parameter which varies between populations, while the wall thickness varies between 100 and 400 microns.

The standard for CABG is the ITA, due to its excellent long-term results. Its high permeability is attributed to the morphological characteristics of the wall, as an elastic artery that has a low probability of developing atherosclerosis and hyperplasia. Furthermore, luminal diameter and wall thickness are similar to the coronary arteries. The left ITA is the first choice for revascularization of the AIA, whereas the right ITA is used most often for the RCA and PIA.

The second best option is the RA, and is most frequently anastomosed with the RCA, the CX, or the PIA, obtaining satisfactory results. Its main advantage is its wide length and thickness, making it a versatile graft and the luminal diameter is similar to the coronary arteries. Its main disadvantage is its propensity to spasm because of its thick muscular tunica media. The UA is used when 
it is not considered safe to extract the RA or when the use of other conduits is not feasible. This vessel has similar morphological characteristics to RA; however, more studies analyzing its permeability and long-term results are needed.

The RGEA is the third best option for CABG. It is mainly used for revascularization of the lower side of the heart, particularly the PIA and the distal RCA. It is a muscular artery; the luminal diameter and wall thickness are somewhat smaller than the coronary arteries. There are few studies about its morphological characteristics and long-term results.

\section{Disclosure Statement}

The authors have no conflict of interest to declare.

\section{References}

1) Mathers CD, Loncar D. Projections of global mortality and burden of disease from 2002 to 2030. PLoS Med 2006; 3: e442.

2) Elizondo Omaña RE, García Rodríguez $M$ de los Ángeles, Morales Gómez JA, et al. Conductos vasculares utilizados en la operación de revascularización miocárdica. Med Univer 2005; 7: 222-5.

3) ElBardissi AW, Aranki SF, Sheng S, et al. Trends in isolated coronary artery bypass grafting: An analysis of the Society of Thoracic Surgeons adult cardiac surgery database. J Thorac Cardiovasc Surg 2012; 143: 273-81.

4) Hinojosa-Amaya JM, Villarreal-Silva EE, ElizondoOmaña RE, et al. Conduits for myocardial revascularization grafts: The importance of morphology and imaging. Med Univ 2010; 12: 115-9.

5) González Santos JM, López Rodríguez J, Dalmau Sorlí MJ, et al. Los injertos arteriales en cirugía coronaria: una terapia universal? Rev Española de Cardiol 2005; 58: 1207-23.

6) Mohr FW, Morice MC, Kappetein AP, et al. Coronary artery bypass graft surgery versus percutaneous coronary intervention in patients with three-vessel disease and left main coronary disease: 5-year follow-up of the randomised, clinical SYNTAX trial. Lancet 2013; 381: 629-38.

7) Diodato M, Chedrawy EG. Coronary artery bypass graft surgery: the past, present, and future of myocardial revascularisation. Surg Res Pract 2014; 2014: 6.

8) Hillis LD, Smith PK, Anderson JL, et al. Special articles: 2011 ACCF/AHA guideline for coronary artery bypass graft surgery: executive summary: a report of the American College of Cardiology Foundation/ American Heart Association Task Force on Practice Guidelines. Anesth Analg 2012; 114: 11-45.
9) Samano N, Geijer H, Liden M, et al. The no-touch saphenous vein for coronary artery bypass grafting maintains a patency, after 16 years, comparable to the left internal thoracic artery: A randomized trial. J Thorac Cardiovasc Surg 2015; 150: 880-8.

10) Gou-Wei H. Considerations in the choice of arterial grafts. In: Gou-Wei H, editor. Arterial grafting for coronary artery bypass surgery. 2nd ed. Berlin, Heidelberg: Springer, 2006; p 81-6.

11) He GW. Arterial grafts for coronary artery bypass grafting: biological characteristics, functional classification, and clinical choice. Ann Thorac Surg 1999; 67: 277-84.

12) Appleson T, Hill RV. Histological comparison of the candidate arteries for bypass grafting of the posterior interventricular artery. Anat Sci Int 2012; 87: 150-4.

13) Rösch J, Rahimtoola SH. Progression of angiographically determined coronary stenosis. Cardiovasc Clin 1977; 8: 55-70.

14) Wang JC, Normand SL, Mauri L, et al. Coronary artery spatial distribution of acute myocardial infarction occlusions. Circulation 2004; 110: 278-84.

15) Herzog C, Zwerner PL, Doll JR, et al. Significant coronary artery stenosis: comparison on per-patient and per-vessel or per-segment basis at 64-section CT angiography. Radiology 2007; 244: 112-20.

16) Mendoza-Rodríguez V, Llerena LR, Rodríguez-de la Vega A, et al. [Volume of coronary calcified plaques by computed tomography and presence of significant stenosis by coronary angiography]. Arch Cardiol Mex 2010; 80: 181-6. (in Spanish)

17) Martínez-González B, Theriot-Girón M del C, LópezSerna N, et al. Morphological analysis of major segments of coronary artery occlusion. Importance in myocardial revascularization surgery. Int J Morphol 2015; 33: 1205-12.

18) Ballesteros Acuña LE, Corzo Gómez EG, Saldarriaga Tellez B, et al. Determinación de la Dominancia Coronaria en Población Mestiza Colombiana. Un Estudio Anatómico Directo. Coronary's Dominance Determination in Racially Mixed Colombian Population. A Direct Anatomical Study. Int J Morphol 2007; 25: 483-91.

19) Ballesteros LE, Ramirez LM, Quintero ID. Right coronary artery anatomy: anatomical and morphometric analysis. Rev Bras Cir Cardiovasc 2011; 26: 230-7.

20) Unlü $Y$, Keleş $P$, Keleş $S$, et al. An evaluation of histomorphometric properties of coronary arteries, saphenous vein, and various arterial conduits for coronary artery bypass grafting. Surg Today $2003 ; \mathbf{3 3}$ : 725-30.

21) Barry MM, Foulon P, Touati G, et al. Comparative histological and biometric study of the coronary, radial and left internal thoracic arteries. Surg Radiol Anat 2003; 25: 284-9.

22) Ilayperuma I, Nanayakkara BG, Palahepitiya KN. Sexual differences in the diameter of coronary arteries in an adult Sri Lankan population. Int J Morphol 2011; 29: $1444-8$. 
23) Aroche Aportela R, Obregón Santos AG, Rodríguez Fontaine Y, et al. Caracterización cualitativa y cuantitativa de las arterias coronarias de la población cubana. Invest Medicoquir 2013; 5: 84-99.

24) Barry M, Touati G, Chardon K, et al. Histologic study of coronary, radial, ulnar, epigastric and internal thoracic arteries: application to coronary artery bypass grafts. Surg Radiol Anat 2007; 29: 297-302.

25) Ballesteros LE, Ramirez LM. Morphological expression of the left coronary artery: a direct anatomical study. Folia Morphol (Warsz) 2008; 67: 135-42.

26) Favaloro RG. Saphenous vein autograft replacement of severe segmental coronary artery occlusion. Ann Thorac Surg 1968; 5: 334-9.

27) Bikdeli B, Hassantash SA, Pourabdollah M, et al. Histopathologic insight into saphenous vein bypass graft disease. Cardiology 2012; 123: 208-15.

28) Herreros J. Cirugía coronaria. Evolución en la última década. Indicaciones y resultados actuales. Rev Española Cardiol 2005; 58: 1107-16.

29) Kelly R, Buth KJ, Légaré JF. Bilateral internal thoracic artery grafting is superior to other forms of multiple arterial grafting in providing survival benefit after coronary bypass surgery. J Thorac Cardiovasc Surg 2012; 144: 1408-15.

30) Japanese Associate for Coronary Artery Surgery (JACAS). Coronary artery surgery results 2013, in Japan. Ann Thorac Cardiovasc Surg 2014; 20: 332-4.

31) Verma S, Lovren F, Pan Y, et al. Pedicled no-touch saphenous vein graft harvest limits vascular smooth muscle cell activation: the PATENT saphenous vein graft study. Eur J Cardiothorac Surg 2014; 45: 717-25.

32) Sepehripour AH, Jarral OA, Shipolini AR, et al. Does a 'no-touch' technique result in better vein patency? Interact Cardiovasc Thorac Surg 2011; 13: 626-30.

33) Souza DS, Johansson B, Bojö L, et al. Harvesting the saphenous vein with surrounding tissue for $\mathrm{CABG}$ provides long-term graft patency comparable to the left internal thoracic artery: results of a randomized longitudinal trial. J Thorac Cardiovasc Surg 2006; 132: 373-8.

34) Spray TL, Roberts WC. Changes in saphenous veins used as aortocoronary bypass grafts. Am Heart J 1977; 94: $500-16$.

35) Thiene G, Miazzi P, Valsecchi M, et al. Histological survey of the saphenous vein before its use as autologous aortocoronary bypass graft. Thorax 1980; 35: 519-22.

36) McCormack D, Ham A. Ham's Histology. 9th ed. Philadelphia: Lippincott Williams \& Wilkins, 1987; p 444.

37) Milroy CM, Scott DJ, Beard JD, et al. Histological appearances of the long saphenous vein. J Pathol 1989; 159: 311-6.

38) Varty K, Jones L, Porter KE, A quantitative study of long saphenous vein morphology in patients undergoing arterial surgery. Phlebology 1995; 10: 90-3.

39) Vineberg AM. Development of an anastomosis between the coronary vessels and a transplanted internal mammary artery. Can Med Assoc J 1946; 55: 117-9.
40) Kneubil MC, Gomes WJ, Aquino MS, et al. Sequential histomorphometric study of the left internal thoracic artery. Brazilian J Cardiovasc Surg 2006; 21: 371-6.

41) Van Son JAM, Smedts FMM, Yang CQ, He GW. Histology and comparison of arterial grafts used for coronary surgery. In: Gou-Wei H, editor. Arterial grafting for coronary artery bypass surgery. 2nd ed. Berlin, Heidelberg: Springer, 2006; p 3-16.

42) Ribeiro MF, Kneubil MC, Aquino MS, et al. [Histomorphometric differences between the left and right internal thoracic arteries in humans]. Rev Bras Cir Cardiovasc 2008; 23: 1-6. (in Portuguese)

43) Borović ML, Borović S, Perić M, et al. The internal thoracic artery as a transitional type of artery: a morphological and morphometric study. Histol Histopathol 2010; 25: 561-76.

44) Kinoshita T, Asai T, Suzuki T, et al. Histomorphology of right versus left internal thoracic artery and risk factors for intimal hyperplasia. Eur J Cardiothorac Surg 2014; 45: 726-31.

45) Henriquez-Pino JA, Gomes WJ, Prates JC, et al. Surgical anatomy of the internal thoracic artery. Ann Thorac Surg 1997; 64: 1041-5.

46) Elizondo Omaña RE, Herrera Correa JA, Leal Lira EM, et al. Comparación anatómica de la arteria torácica interna con la arteria radial. Med Univer 2003; 5: 83-6.

47) Baikoussis NG, Papakonstantinou NA, Apostolakis E. Radial artery as graft for coronary artery bypass surgery: Advantages and disadvantages for its usage focused on structural and biological characteristics. J Cardiol 2014; 63: 321-8.

48) Reyes Hernández CG, Velázquez Gauna SV, Bazaldúa Cruz JJ, et al. Estudio Morfométrico de la Arteria Radial y su Implicación en la Cirugía de Revascularización Miocárdica. Int J Morphol 2013; 31: 791-6.

49) Carpentier A, Guermonprez JL, Deloche A, et al. The Aorta-to-coronary radial artery bypass graft. Ann Thorac Surg. 1973; 16: 111-21.

50) Gaudino M, Crea F, Cammertoni F, et al. Morphofunctional features of the radial artery: implications for use as a coronary bypass conduit. Ann Thorac Surg 2014; 98: 1875-9.

51) Chowdhury UK, Airan B, Mishra PK, et al. Histopathology and morphometry of radial artery conduits: basic study and clinical application. Ann Thorac Surg 2004; 78: 1614-21.

52) Nasr AY. The radial artery and its variations: anatomical study and clinical implications. Folia Morphol (Warsz) 2012; 71: 252-62.

53) Acar C. Radial artery: Clinical results. In: Gou-Wei $\mathrm{H}$, editor. Arterial grafting for coronary artery bypass surgery. 2nd ed. Berlin, Heidelberg: Springer, 2006; p 165-9.

54) Buxton BF, Chan AT, Dixit AS, et al. Ulnar artery as a coronary bypass graft. Ann Thorac Surg 1998; 65: $1020-4$. 
55) Riekkinen HV, Karkola KO, Kankainen A. The radial artery is larger than the ulnar. Ann Thorac Surg 2003; 75: 882-4.

56) Necomb A, Oqueli E, Buxton BF. Ulnar artery as a coronary artery bypass graft: five year experience. In: $\mathrm{He}$ GW, editor. Arterial grafting for coronary artery bypass surgery. 2nd ed. Springer Berlin Heidelberg, 2006; p 227-32.

57) Nie M, Ohara K, Miyoshi Y, et al. Ulnar artery graft for myocardial revascularization. Jpn J Thorac Cardiovasc Surg 2000; 48: 112-4.

58) Hinojosa Amaya JM, Elizondo Omaña RE, García Rodríguez MDLÁ, et al. Características anatómicas de la arteria cubital: longitud, diámetro y ramos musculares. Med Univer 2005; 7: 67-70.

59) Bailey CP, Hirose T, Aventura A, et al. Revascularization of the ischemic posterior myocardium. CHEST J. 1967; 52: 273-85.

60) Edwards W, Blakeley W, Lewis C. Technique of coronary bypass with autogenous arteries. J Thorac Cardiovasc Surg 1973; 65: 272-5.
61) Pym J. Right gastroepiplioc artery grafting: history and operative techiniques. In: He GW, editor. Arterial grafting for coronary artery bypass surgery. 2nd ed. Springer Berlin Heidelberg, 2006; p 181-92.

62) Ito $S$, Yamaguchi $S$, Saeki H, et al. Significance of preoperative evaluation of the right gastroepiploic artery graft to the coronary artery in patients undergoing abdominal surgery. World J Surg 2014; 38: 1051-7.

63) Phung DV, Kinoshita T, Asai T, et al. Histological and morphometric properties of skeletonized gastroepiploic artery and risk factors for intimal hyperplasia. Innovations (Phila) 2012; 7: 191-4.

64) Malvindi PG, Jacob S, Kallikourdis A, et al. What is the patency of the gastroepiploic artery when used for coronary artery bypass grafting? Interact Cardiovasc Thorac Surg 2007; 6: 397-402.

65) Gou-Wei H. Rarely or possibly used arterial grafting. In: Gou-Wei H, editor. Arterial grafting for coronary artery bypass surgery. 2nd ed. Berlin, Heidelberg: Springer, 2006; p 215-42. 